\title{
Effect of a Comprehensive Health Education Program to Increase Physical Activity among Primary School Students in China
}

\author{
Ling Qian', Lok-Wa Yuen², Yonghua Feng², Ian M. Newman'², Duane F. Shell², Weijing Du1 \\ ${ }^{1}$ China Center for Health Education, Ministry of Health, Beijing, China \\ ${ }^{2}$ Department of Educational Psychology, University of Nebraska-Lincoln, Lincoln, Nebraska, USA \\ Email: *inewman1@unl.edu, qianlingzh@126.com
}

How to cite this paper: Qian, L., Yuen, L.-W., Feng, Y. H., Newman, I. M., Shell, D. F., \& Du, W. J. (2018). Effect of a Comprehensive Health Education Program to Increase Physical Activity among Primary School Students in China. Advances in Physical Education, 8, 193-204. https://doi.org/10.4236/ape.2018.82018

Received: April 18, 2018

Accepted: May 21, 2018

Published: May 24, 2018

Copyright (c) 2018 by authors and Scientific Research Publishing Inc. This work is licensed under the Creative Commons Attribution International License (CC BY 4.0).

http://creativecommons.org/licenses/by/4.0/

(c) (i) Open Access

\begin{abstract}
China's National Physical Fitness and Health Surveillance (NPFHS) survey revealed high levels of sedentary behavior among primary school-aged children. Sedentary behavior is linked to both short-term and long-term physical and mental health conditions. A comprehensive school health education program was designed and its effectiveness to raise physical activity levels in Grade 4 primary school children was evaluated. Twelve schools ( 6 of program, 6 of control) from six cities in two economically different provinces were selected. Students at program schools received physical activity instruction both in and out of school. Control schools carried on with their usual level of physical activity for students, as required by national educational standards. Program effectiveness was assessed by comparing students' physical activity behaviors at pre- and post-program, and by comparing students' physical activity scores at program schools with students' scores at control schools. The pre-program survey of students' behaviors was done at the end of Grade 3, and the post-program survey was done at the end of Grade 4. Multi-level modeling was used to evaluate program effectiveness to allow for missing data. Results from 4472 students showed at pre-program there was no difference in control and program schools' student physical activity scores. At post-program students in program schools did significantly more physical activity compared to students in control schools. Students in program schools were more physically active after the comprehensive school health education program. A school-based comprehensive health education program would effectively increase children's physical activity level in China. There is a potential to reduce sedentary behavior among children by implementing school programs that are environmental in nature; that is, activities involve not only the students, but also the school administration, teachers, parents, and community members.
\end{abstract}




\section{Keywords}

Obesity, Child, Sedentary, Environmental, Health Promotion, Multilevel Modeling

\section{Introduction}

Negative relationships between physical activity and obesity are consistently reported in many countries including China (Cui, Hardy, Dibley, \& Bauman, 2011; Janssen, Katzmarzyk, Boyce, Vereecken, Mulvihill, Roberts et al., 2005; Li, Lin, Guo, Huang, Wu, Zhang et al., 2014; Qin, 2014). The prevalence of child obesity is rising in China (Song, Wang, Ma, \& Wang, 2013), and Chinese children are increasingly sedentary (Cui, Hardy, Dibley, \& Bauman, 2011). The 2010 China National Physical Fitness and Health Surveillance Survey (NPFHS) reported that only $22.7 \%$ of primary and middle schools students were physically active for 60 minutes or more per day. Among students aged $9-12$, more urban students (37.6\%) were physically active than rural students (32.0\%), and time spent on exercising declined with age (Song, Zhang, Yang, Zhang, Dong, \& Ma, 2012; Zhang, Song, Yang, Zhang, Dong, \& Ma, 2012). A separate study in 10 cities confirmed that physical activity declined when grade in school rose (Chen, Zheng, Yi, \& Yao, 2014). Apart from its relationship to obesity and other physical health indicators, physical activity has other benefits, including improved mental health and improved academic performance (Penedo \& Dahn, 2005; Rasberry, Lee, Robin, Laris, Russell, Coyle et al., 2011).

Children's physical activity is affected by internal and external factors. These include: how much a child personally likes physical education classes, sports and extracurricular activities, parental support for and encouragement of physical activity, the availability of facilities and opportunities to be active, a school environment that encourages children to be active, administrative scheduling that allows for $60+$ minutes per school day for physical activities, and assigning quantities of homework that restrict play outside of school hours (Ren, Zhou, Liu, Wang, \& Yin, 2016; Zhang, Song, Yang, Zhang, Dong, \& Ma, 2012; Rasberry, Lee, Robin, Laris, Russell, Coyle et al., 2011). These findings have been confirmed in a small number of regional surveys in China (Duan, $\mathrm{Hu}$, Wang, \& Arao, 2015; Wang, Hui, Terry, Ma, Cheng, Ding et al., 2016; Li, Dibley, Sibbritt, $\&$ Yan, 2006).

The NPFHS data identified individual attitudes about physical activity as being especially related to activity level. Students who liked physical education class were more likely to be physically active every day compared to students who didn't like it $(23.7 \%$ vs. $15.9 \%)$ and more likely to participate in running exercises (26.9\% vs. 12.1\%) (Zhang, Song, Yang, Zhang, Dong, \& Ma, 2012).

\section{Comprehensive Approach to Health Behavior Change}

Two conceptually different options are available for increasing physical activity 
of young people in school. The first is to provide effective instruction about the values of physical activity to students, and provide knowledge, skills and motivation to change their own physical activity levels. The second is a holistic approach, sometimes referred as comprehensive school health education, that includes effective instruction for developing knowledge, skills and motivation and also changes to the school's physical and social environment. This type of program incorporates the long-standing public health principle that changes to the environment are an essential part of any program to change an individual's behaviors.

Qian, Newman, Shell \& Cheng (2012) reported the result of an experiment in China to reduce obesity and overweight among school-age children. Their data provided evidence that changing the school environment, including involving parents, families, teachers and community members, was feasible and effective. Their program, based on the World Health Organization's Health Promoting Schools Model, increased student knowledge, improved attitudes, and affected behaviors across all assessment periods. Other studies have confirmed the importance of parent and family involvement in programs of this type (Wang, Sun, \& Zhao, 2016; Wang, Liu, Ren, Lv, \& Li, 2015). Other studies have confirmed that even small-scale, classroom-based interventions may be useful in slowing the rise of childhood obesity in China (Liu, Hu, Ma, Cui, Pan, Chang et al., 2007; Li, Hu, Schoute, Liu, Du, Li et al., 2010).

The comprehensive school health education program described in this paper was developed to increase physical activity and healthy eating behaviors among Chinese primary school students. To increase the usefulness of the results, this study was completed in two different regions of China. In this paper, we report the results of the program on students' physical activity levels. The effects of the program on students' eating behaviors is reported separately (Qian, Newman, Yuen, Du, \& Shell, 2018). Children's physical activity is to a larger degree under the control of the individual child, compared to children's eating behaviors that are generally managed by parents, families, and other adults in the child's life.

\section{Method}

\subsection{Study Setting}

Two economically different provinces were arbitrarily chosen to implement this comprehensive health education program: Shandong and Qinghai. Shandong has the $3^{\text {rd }}$ highest provincial GDP in China, Qinghai has the second lowest GDP and a number of ethnic minority groups (National Bureau of Statistics of China, n.d.). In each province, three cities of different sizes were chosen, then two primary schools were selected within each city. Two primary schools in each city were paired, and one school was randomly assigned as the program school and the other as the control. The program schools carried out the newly-designed comprehensive health education program, while the control schools continued their normal school activities, which included some physical activity instruction 
as required by the Ministry of Education. To be eligible to participate schools had to meet the following criteria: never conducted a health/physical education project or diet/nutrition related project before, have more than 1000 students enrolled, and have the school principal's consent to cooperate with the project team throughout the study. A total of 12 schools participated.

\subsection{The Comprehensive Health Education Program}

The Ministry of Education requires schools to provide one hour of physical activity for students each day; how this standard is met is left up to schools. The objective of the comprehensive health education program in this study is to encourage students to be active beyond the one-hour minimum. To meet this objective, the project proceeded through three stages: program development, program implementation, and program evaluation.

Program Development. In 2013, in each program school, a school health committee was established. The school health committees consisted of school leaders, parent representatives, community leaders, and representatives of the city bureau of health and city bureau of education. Technical support to the school health committees was provided throughout the project by a team of experts from the China Center for Health Education (CCHE). The program development process started with discussions with teachers, school staff, parents and community leaders. Then, with assistance from the CCHE team, the school health committees developed a Handbook for Youth Exercise and Nutrition that outlined the aspirations of the project: 1) integrate physical activity and good nutrition into health classes; 2) encourage and supervise students to practice what is taught in physical education classes; 3 ) provide programs about physical activity and nutrition for parents and teachers based on the content of the Handbook, 4) distribute bulletins about physical activity and nutrition; 5) use social media to distribute physical activity/nutrition information; 6) conduct a formal class on physical activity; 7) hold a sports day involving students and parents; and 8) report students' physical activity behaviors to parents. The Handbook also suggested additional elective activities.

Program Implementation. At the next stage, a work group was established at each program school. The school work group, consisting of class teachers, physical education teachers, school doctors, health teachers, professionals from the community health bureau, and other school staff, created a plan of program activities specifically for their school, carried out the activities, and worked to ensure that all parts of the comprehensive health education program were fully implemented. Each school work group was under the leadership of the school principal, who had the authority to adjust the program to accommodate local conditions. The program was implemented for one school year (Sept 2014-June 2015) in the $4^{\text {th }}$ grade.

Program Evaluation. Program implementation was monitored by personnel from the local bureaus of health and the provincial- and city-level centers for 
disease control and prevention. The outcome evaluation was done with a preand post-program survey of student behaviors. Additional assessments included discussions with teachers, meetings with representatives of all school personnel involved in the program, meeting with students, and reviewing daily records of program activities carried out by the schools. The objective of the evaluation, in addition to assessing student physical activity levels pre- and post-program, was to identify difficulties in program implementation and opportunities for program improvement.

\subsection{Student Activity Measures}

On a paper-and-pencil survey students recorded their levels of engagement in six physical activity-related behaviors. The six behaviors (and their acceptable level criteria) were: activity during class break (most of the time), physical activity after school (almost every day), sports time per day ( $\geq 60$ minutes), sedentary time after school ( $<1$ hour), sedentary time during weekend ( $<1$ hour), frequency of physical activity during weekend (often/always). These recommended levels of daily physical activity were based on the Dietary Guidelines for Chinese Residents (Chinese Nutrition Society, 2010). A score of 1 was given if a student's reported activity met the recommended criterion, and a score of 0 was given for no report and if the student's activity did not meet the recommended criterion. The total score was the number of physical activity-related behaviors for which the student met the recommended criterion, with a maximum score of 6 .

Pre-program data were gathered in May 2014 from all students in $3^{\text {rd }}$ grade in program and control schools in the year prior to the program implementation. Post-program data were gathered again at the end of $4^{\text {th }}$ grade in June of 2015.

\subsection{Data Analysis}

Descriptive analysis of student physical activity scores for program and control, pre- and post-, in each province was calculated using SPSS version 25. The Time $\times$ Intervention interaction effect on students' activity level was examined with a two-level model using MIXED procedure in SAS Version 9.4. Since many students changed classrooms at $4^{\text {th }}$ grade, crossed random effects of students and classrooms were included in the model. Time (pre-program and post-program) was the predictor at Level 1 . Intervention (control and program) was the predictor at Level 2. Multilevel modeling was chosen as the method of analysis because it does not require equal numbers of students in both pre- and post-program. Therefore, students who missed either the pre-program survey or the post-program survey were not excluded from the analysis but contributed less to the results (Raudenbush \& Bryk, 2002). The detailed model and equation is appended to this report (see Appendix).

\subsection{Ethical Considerations}

The study was not a research project, but an evaluation of educational practices in educational settings. Permissions were obtained prior to the program from 
health and education authorities in each city.

The analysis of the students' survey data was considered research and was conducted with a de-identified dataset by a team of faculty and Chinese graduate students of the Nebraska Prevention Center for Alcohol and Drug Abuse in the Department of Educational Psychology at the University of Nebraska-Lincoln (USA). The data analysis stage of this project was approved by Institutional Review Board of the University of Nebraska-Lincoln (IRB Approval \#:20151215742 $\mathrm{EX})$.

\section{Results}

In total, 7439 observations were collected from $44724^{\text {th }}$-grade students (average age 10 - 11 years old): 2967 students completed both pre- and post-survey, 720 students completed the pre-survey only, and 785 students completed the post-survey only. In this sample, there were $2843(63.6 \%)$ students from Shandong and 1629 (36.4\%) students from Qinghai; 2076 (46.4\%) students were in program schools and 2396 (53.6\%) students were in control schools; 2067 (46.2\%) male and 1792 (40.1\%) female, with 613 (13.7\%) not reporting gender.

Table 1 shows the average number of physical activity-related behaviors that met the recommended criteria at pre- and post-program for program and control schools in each province. In both Shandong and Qinghai, students in the control schools on average met recommended levels for 3 behaviors at both preand post-program. Students in the program schools in Shandong on average met the recommended criteria on 3 behaviors at pre-program and 4 behaviors at post-program. In Qinghai, in the program schools, students on average met recommended criteria on 2 behaviors at pre-program and on 3 behaviors at post-program.

Table 2 shows a significant interaction effect between intervention and time, indicating that the pre- to post-program change in activity behaviors were different for students in the program and control schools.

More analysis was done to understand in more details how student activity-related behavior change differed between students in the program and control schools (Table 3). Before intervention, there was no difference in activity behaviors between students in control and program schools. After intervention, students in program schools had higher scores than students in control schools. Also, students in program schools had a significant positive change in activity behaviors from pre- to post-program $(p=0.0001)$.

\section{Discussion}

In this study, the change in student activity-related behaviors, over time, was greater at program schools than at control schools. Students in program schools were more active after the comprehensive school health education program. This was similar to the finding of Qian et al.'s (2012) evaluation of an earlier 
Table 1. Average number of children's physical activity behaviors meeting the recommended level (of 6 possible) by province and by program-control at pre- and post-program.

\begin{tabular}{ccccc}
\hline & \multicolumn{2}{c}{ CONTROL } & \multicolumn{2}{c}{ PROGRAM } \\
\cline { 2 - 5 } & Mean & $S D$ & Mean & $S D$ \\
\hline Shandong & & & 2.66 & 1.39 \\
\hline pre-program & 2.57 & 1.43 & 3.71 & 1.69 \\
post-program & 2.52 & 1.41 & & \\
\hline Qinghai & & & 2.38 & 1.31 \\
\hline pre-program & 2.69 & 1.40 & 3.11 & 1.58 \\
post-program & 2.50 & 1.38 & & \\
\hline
\end{tabular}

Table 2. Fixed effects from multilevel model.

\begin{tabular}{|c|c|c|c|c|c|}
\hline & Coefficient $(\gamma)$ & S.E. & df & $t$ & $p$ \\
\hline Intercept & 3.66 & 0.32 & 17.1 & 11.57 & $<0.001$ \\
\hline \multicolumn{6}{|l|}{ Time } \\
\hline pre-program & -0.95 & 0.22 & 11.1 & -4.41 & 0.001 \\
\hline post-program & Ref & --- & --- & --- & --- \\
\hline \multicolumn{6}{|l|}{ Intervention } \\
\hline Control & -1.01 & 0.32 & 12.8 & -3.16 & 0.008 \\
\hline Program & Ref & --- & --- & --- & --- \\
\hline \multicolumn{6}{|l|}{ Province } \\
\hline Shandong & 0.11 & 0.15 & 8.77 & 0.71 & 0.497 \\
\hline Qinghai & Ref & --- & --- & --- & --- \\
\hline $\begin{array}{c}\text { Time }{ }^{*} \text { Intervention } \\
\text { (pre }{ }^{\star} \text { control) }\end{array}$ & 1.06 & 0.3 & 10.8 & 3.49 & 0.005 \\
\hline
\end{tabular}

Note: Satterthwaite approximation was used for denominator degrees of freedom.

Table 3. Estimated mean differences among program and control and pre- and postprogram scores.

\begin{tabular}{ccccccc}
\hline 1 & 2 & $\begin{array}{c}\text { Mean Difference } \\
(1-2)\end{array}$ & S.E. & df & $t$ & $p$ \\
\hline Pre, Control & Pre, Program & 0.05 & 0.15 & 8.88 & 0.33 & 0.750 \\
Pre, Control & Post, Control & 0.11 & 0.21 & 10.6 & 0.05 & 0.627 \\
Pre, Program & Post, Program & -0.95 & 0.22 & 11.1 & -4.41 & 0.001 \\
Post, Control & Post, Program & -1.01 & 0.32 & 12.8 & -3.16 & 0.008 \\
\hline
\end{tabular}

school-based comprehensive health education program designed to reduce obesity and overweight. While the pre-post, program-control differences in this study were not great, we believed they are significant in light of the data from the 2010 China National Physical Fitness and Health Surveillance (NPFHS) survey 
that indicated time spent on exercising declined with age (Song, Zhang, Yang, Zhang, Dong, \& Ma, 2012; Zhang, Song, Yang, Zhang, Dong, \& Ma, 2012). The results suggest that implementing comprehensive school health education in China might prevent or reverse decline in activity among older children.

The increased physical activity level was seen among students in program schools in two economically, ethnically, and geographically different regions, which suggests effective school health education to increase children's physical activity is possible in diverse settings. The school principals were allowed to make some modifications to their school's implementation plan to accommodate local conditions, which suggested that comprehensive school health programs could produce positive effects while allowing flexible implementation, as long as the fidelity to the eight core elements listed in the program Handbook was maintained.

Noticeably, the measure for sedentary time during weekend ( $<1$ hour) was the least changed by the one-year comprehensive school health program. Only one-third of the students reported less than one hour of sedentary time during weekends in Shandong and Qinghai. This may reflect that Chinese students are heavily burdened with academic-related activities outside of school hours. A survey study in five metropolitan cities in China found that primary school students on average spent 2.35 hours on homework and 2.19 hours on remedial academic work during weekend (Ren, Zhou, Liu, Wang, \& Yin, 2016). Easy access to mobile devices may also increase the time that children are sedentary, such as when they are watching TV and playing games. On average, primary school students reported spending 1.8 hours on screen viewing during weekends (Ren et al., 2016).

Although the educational activities were not novel, limited resources and efforts did make implementation difficult. The team monitoring the implementation found the schools' most frequent challenges were finding sufficient space for all students to be active, finding time to coordinate activities, and finding ways to integrate physical activities with other classroom activities. Not all schools were equally successful in providing the programs for parents and distributing bulletins and social media messages about physical activity. This was especially true for the schools in Qinghai. All program schools were given assistance from local government agencies and the CCHE, so no significant additional investment in materials or personnel was required for schools to implement the comprehensive health education program.

Overall these results should be encouraging for those seeking ways to increase physical activity among primary school students through comprehensive school health education.

\section{Limitations}

While the results are encouraging it must be acknowledged that a significant amount of professional time for the development, implementation, and evaluation of this comprehensive health education program was provided by national 
and local experts. It is unlikely that this could be duplicated for other regions. However these results do suggest an effective model that could be adopted by schools in other parts of the country without the need to duplicate the entire program development effort. Nevertheless producing a comprehensive health education program like this, because it is unusual, will require significant administrative commitment.

Comprehensive health education programs present a challenge for evaluation and the interpretation of positive results. The obvious challenge is tracking students over sufficient time to estimate effectiveness. A second challenge is determining how the many individual elements incorporated into a comprehensive health education program contribute to its overall effectiveness. For this program, there was no way of learning which of the individual elements in the program was responsible for positive changes in students' activity levels, or of finding out how much each element may have contributed to the changes. In addition, it was not possible to assess the effects of the additional assistance that came from the CCHE team, the provincial bureau of health, or the local bureau of health, either for their technical contribution or for the effects of the additional attention that administrators, teachers, and students received from the outside visitors. To measure the effect of individual program elements would require a long period of evaluation in which various elements are either withdrawn or added and the interface with external experts is carefully monitorednot feasible for school-based programs.

From the results it was evident that the students in the program schools in both provinces benefited from the comprehensive health education program, but the benefits were greater for students in Shandong, which is the more economically advantaged of the two provinces. The reasons for the difference in degree of improvement were not explored.

The evaluation did not attempt to measure changes in knowledge or attitude about physical activity among school personnel, students, their parents, or families.

\section{Conclusion}

This project demonstrated that a comprehensive health education program, which included classroom instruction, school administrators, staff, teachers, and parents, community health and education bureau assistance, and changes in the school's physical and social environment, could increase physical activity among primary school students. This project suggests it could serve as model program that could be further refined. Based on these results and the results reported by Qian et al. (2012), we recommend that a task force of educators, health and evaluation specialists designs a number of small longitudinal studies that explore the effects of similar programs on students followed over time and more carefully accounting for possible confounding variables. The successive approximations resulting from such an approach would suggest a clear direction for developing programs to serve larger populations of primary school students. 


\section{References}

Chen, Y., Zheng, Z., Yi, J., \& Yao, S. (2014). Associations between Physical Inactivity and Sedentary Behaviors among Adolescents in 10 Cities in China. BMC Public Health, 14, 744. https://doi.org/10.1186/1471-2458-14-744

Chinese Nutrition Society (2010). Dietary Guidelines for Chinese Residents. Lhasa: Tibetan People's Press. (In Chinese)

Cui, Z., Hardy, L. L., Dibley, M. J., \& Bauman, A. (2011). Temporal Trends and Recent Correlates in Sedentary Behaviours in Chinese Children. The International Journal of Behavioral Nutrition and Physical Activity, 8, 93. https://doi.org/10.1186/1479-5868-8-93

Duan, J., Hu, H., Wang, G., \& Arao, T. (2015). Study on Current Levels of Physical Activity and Sedentary Behavior among Middle School Students in Beijing, China. PLoS One, 10, e0133544. https://doi.org/10.1371/journal.pone.0133544

Janssen, O., Katzmarzyk, P. T., Boyce, W. F., Vereecken, C., Mulvihill, C., Roberts, C. et al. (2005). Comparison of Overweight and Obesity Prevalence in School-Aged Youth from 34 Countries and Their Relationships with Physical Activity and Dietary Patterns. Obesity Reviews, 6, 123-132. https://doi.org/10.1111/j.1467-789X.2005.00176.x

Li, H., Lin, S., Guo, H., Huang, Y., Wu, L., Zhang, Z., Ma, J., \& Wang, H. (2014). Effectiveness of a School-Based Physical Activity Intervention on Obesity in School Children: A Nonrandomized Controlled Trial. BMC Public Health, 14, 1282. https://doi.org/10.1186/1471-2458-14-1282

Li, M., Dibley, M. J., Sibbritt, D., \& Yan, H. (2006). Factors Associated with Adolescents' Physical Inactivity in Xi'an City, China. Medicine and Science in Sports and Exercise, 38, 2075-2085. https://doi.org/10.1249/01.mss.0000233802.54529.87

Li, Y.-P., Hu, X.-Q., Schouten, E. G., Liu, A.-L., Du, S.-M., Li, L.-Z. et al. (2010). Report on Childhood Obesity in China (8): Effects and Sustainability of Physical Activity Intervention on Body Composition of Chinese Youth. Biomedical and Environmental Sciences, 23, 180-187. https://doi.org/10.1016/S0895-3988(10)60050-5

Liu, A.-L., Hu, X.-Q., Ma, G.-S., Cui, Z.-H., Pan, Y.-P., Chang, S.-Y. et al. (2007). Report on Childhood Obesity in China (6) Evaluation of a Classroom-Based Physical Activity Promotion Program. Biomedical and Environmental Sciences, 20, 19-23.

National Bureau of Statistics of China (n.d.). China Regional Economic Development Visual Statistics Website. http://data.stats.gov.cn/english/swf.htm? $\mathrm{m}=$ turnto\&id=3

Penedo, F. J., \& Dahn, J. R. (2005). Exercise and Well-Being: A Review of Mental and Physical Health Benefits Associated with Physical Activity. Current Opinion in Psychiatry, 18, 189-193. https://doi.org/10.1097/00001504-200503000-00013

Qian, L., Newman, I. M., Shell, D. F., \& Cheng, M. J. (2012) Reducing Overweight and Obesity among Elementary Students in Wuhan, China. International Electronic Journal for Health Education, 15, 62-71.

https://digitalcommons.unl.edu/edpsychpapers/242/

Qian, L., Newman, I. M., Yuen, L.-W., Du, W., \& Shell, D. F. (2018). Effects of a Comprehensive Nutrition Education Program to Change Grade School Students' Eating Behaviors in China. Unpublished Draft Manuscript.

Qin, L. (2014). Evaluation on the Exercise and Nutrition Intervention among Overweight and Obesity Adolescents. Xian daiyu fang yixue [Modern Preventive Medicine], 41, 1597-1604. (In Chinese)

Rasberry, C. N., Lee, S. M., Robin, L., Laris, B. A., Russell, L .A., Coyle, K. K., \& Nihiser, A. J. (2011). The Association between School-Based Physical Activity, Including Phys- 
ical Education, and Academic Performance: A Systematic Review of the Literature. Preventive Medicine, 52, S10-S20. https://doi.org/10.1016/j.ypmed.2011.01.027

Raudenbush, S. W., \& Bryk, A. S. (2002). Hierarchical Linear Models: Applications and Data Analysis Methods (2nd ed.). Thousand Oaks, CA: Sage Publishing.

Ren, H., Zhou, Z. Liu, W., Wang, X., \& Yin, Z. (2016). Excessive Homework, Inadequate Sleep, Physical Inactivity and Screen Viewing Time Are Major Contributors to High Pediatric Obesity. Acta Paediatrica, 106, 120-127.

Song, Y., Wang, H., Ma, J., \& Wang, Z. (2013). Secular Trends of Obesity Prevalence in Urban Chinese Children from 1985 to 2010: Gender Disparity. PLOS ONE, 8, e53069. https://doi.org/10.1371/journal.pone.0053069

Song, Y., Zhang, X., Yang, T., Zhang, B., Dong, B., \& Ma, J. (2012). Current Situation and Cause Analysis of Physical Activity in Chinese Primary and Middle School Students in 2010. Chinese Journal of Peking University, 44, 347-354. (In Chinese)

Wang, L., Sun, J., \& Zhao, S. (2016). Parental Influence on the Physical Activity of Chinese Children Do Gender Differences Occur? European Physical Education Review, 23, 110-126.

Wang, X. Q., Hui, Z. Z., Terry, P. D., Ma, M., Cheng, L., Deng, F., Gu, W., \& Zhang, B. (2016). Correlates of Insufficient Physical Activity among Junior High School Students: A Cross-Sectional Study in Xi'an, China. International Journal of Environmental Research and Public Health, 13, 397. https://doi.org/10.3390/ijerph13040397

Wang, X., Liu, Q., Ren, Y., Lv, J., \& Li, L. (2015). Family Influences on Physical Activity and Sedentary Behaviours in Chinese Junior High School Students: A Cross-Sectional Study Health Behavior, Health Promotion and Society. BMC Public Health, 15, 287. https://doi.org/10.1186/s12889-015-1593-9

Zhang, X., Song, Y., Yang, T., Zhang, B., Dong, B., \& Ma, J. (2012). Analysis of Current Situation of Physical Activity and Influencing Factors in Chinese Primary and Middle School Students in 2010. Chinese Journal of Preventive Medicine, 46, 781-788. (In Chinese) 


\section{Appendix. Multilevel Model Analysis and Equations}

$$
\begin{aligned}
Y_{i j k l}= & \gamma_{0000}+\gamma_{1000} \text { Time }_{i j k l}+\gamma_{0001} \text { Intervention }_{l}+\gamma_{0002} \text { Province }_{l} \\
& +\gamma_{1001} \text { Time }_{i j k l} \times \text { Intervention }_{l}+e_{i j k l}+u_{0 j k l}+u_{1 j k l} \text { Time }_{i j k l} \\
& +u_{00 k l}^{\text {Pre }} d_{i j k l}^{\text {Pre }}+u_{00 k l}^{\text {Post }} d_{i j k l}^{\text {Post }}+u_{000 l}+u_{100 l} \text { Time }_{i j k l}
\end{aligned}
$$

where $Y_{i j k l}$ is the physical activity behavior score at the $i^{\text {th }}$ time point for the $j^{\text {th }}$ student in the $k^{\text {th }}$ classroom and $l^{\text {th }}$ school; Time Tijkl $_{\text {is }}$ is a dummy variable distinguishing the pre- and post-test measurements with the post-test as the reference group; Intervention ${ }_{l}$ is a dummy variable distinguishing the control and treatment groups with the treatment group as the reference; Province, is a dummy variable distinguishing Shandong and Qinghai province with Shandong as the reference; $\gamma_{1000}, \gamma_{0001}, \gamma_{0002}$ and $\gamma_{1001}$ are the corresponding main and interaction effects; $e_{i j k l} \sim N\left(0, \sigma^{2}\right)$ is the Level 1 residual effect; $u_{0 j k l} \sim N\left(0, \tau_{0}^{j}\right)$ and $u_{1 j k l} \sim N\left(0, \tau_{1}^{j}\right)$ are the Level 2 student random intercept and slope effects, respectively; $u_{00 k l}^{\text {Pre }} \sim N\left(0, \tau_{0}^{\text {Pre }, k}\right)$ and $u_{00 k l}^{\text {Post }} \sim N\left(0, \tau_{0}^{\text {Post }, k}\right)$ are the time-specific (acute) Level 2 classroom random intercept effects activated at the respective time points by the dummy variables $d_{i j k l}^{\text {Pre }}$ and $d_{i j k l}^{\text {Post }}$; and $u_{000 l} \sim N\left(0, \tau_{0}^{l}\right)$ and $u_{100 l} \sim N\left(0, \tau_{1}^{l}\right)$ are the Level 3 school random intercept and slope effects, respectively. Due to the small $n$ of Level 3, residual maximum likelihood (REML) estimation was used to ensure appropriate estimation of the variance terms. Denominator degrees of freedom were computed using the Satterthwaite approximation. 